\title{
Detection of Leishmania (Viannia) DNA in leucocytes from the blood of patients with cutaneous leishmaniasis
}

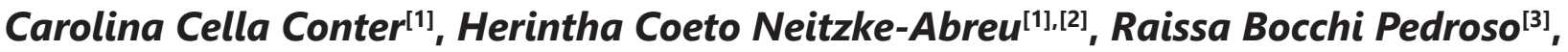 \\ Maria Valdrinez Campana Lonardoni ${ }^{[1],[3]}$, Thaís Gomes Verzignassi Silveira ${ }^{[1],[3]}$ \\ and Sandra Mara Alessi Aristides ${ }^{[1],[3]}$
}

[1]. Programa de Pós-Graduação em Ciências da Saúde, Universidade Estadual de Maringá, Maringá, Paraná, Brazil. [2]. Faculdade de Ciências da Saúde, Universidade Federal da Grande Dourados, Dourados, Mato Grosso do Sul, Brazil. [3]. Departamento de Análises Clínicas e Biomedicina, Universidade Estadual de Maringá, Maringá, Paraná, Brazil.

\begin{abstract}
Introduction: Cutaneous leishmaniasis (CL) is a serious and global public health issue, with the potential of developing a mucosal form, occurring as subclinical cases, and showing recurrence despite previous treatment. Methods: Polymorphonuclear and mononuclear DNA obtained from 49 patients was subjected to polymerase chain reaction for detection of Leishmania (Viannia). Results: DNA was detected in mononuclear cells from two patients with active primary lesions positive for CL, with infection periods of 3 and 6 months, respectively. Conclusions: The DNA of Leishmania (Viannia) indicates probable parasite dissemination possibly explaining subclinical case emergence, lesion recurrence, and mucosal lesion appearance.
\end{abstract}

Keywords: Polymerase chain reaction. Leishmania (Viannia). Leucocyte.

Leishmaniasis has been reported in 98 countries worldwide. Approximately 14 million people are infected and 350 million people are at risk of infection ${ }^{(1)}$. Cutaneous leishmaniasis (CL) is an important dermatosis that has been reported in every State of Brazil ${ }^{(2)}$. In State of Paraná, CL is endemic and most cases are caused by Leishmania (Viannia) braziliensis, which has the potential to develop as a mucosal form of the disease ${ }^{(2)(3)}$. The mucosal form of CL, which manifests as destructive and mutilating injuries in the mucous membranes of the upper airways, is estimated to occur in 3-5\% of cases ${ }^{(2)}$. In State of Paraná, the mucosal form was identified in $23.1 \%$ of cases in 2010 , indicating a higher prevalence of this form of the disease compared to other Brazil States ${ }^{(4)}$.

Mucosal lesions result from the dissemination of the pathogen from the primary cutaneous lesion. These lesions usually appear years after the primary lesion has healed and can occur owing to inadequate treatment of the primary lesions or a failure of cellular immunity ${ }^{(2)}$. The parasite can persist for years in the host organism, spreading in the blood and lymphatic system $^{(5)(6)}$. This is the most probable mechanism to explain the occurrence of metastatic forms (mucosal and recurrent

Corresponding author: Dra. Sandra Mara Alessi Aristides. Av. Colombo 5790, 87020-900 Maringá, Paraná, Brasil.

Phone: 5544 3011-4878; Fax: 5544 3011-4860

e-mail: smaaristides@uem.br

Received 25 February 2015

Accepted 16 April 2015 cutaneous lesions), which justifies the search for parasites in the blood, especially in monocytes and neutrophils, as they are the main cells involved in a host's initial defense.

Therefore, in order to better understand the mechanisms of persistence of the parasite and the pathogenesis of the disease, we used polymerase chain reaction (PCR) in this study to investigated the presence of Leishmania (Viannia) in polymorphonuclear and mononuclear cells in the peripheral blood of patients with CL.

The study included 49 patients residing in endemic areas and diagnosed with CL who had been referred to the $15^{\text {th }}$ Regional Health Unit of State of Paraná between June and December 2012. Diagnoses were made at the Laboratório de Ensino e Pesquisa em Análises Clínicas of the Universidade Estadual de Maringá, which is the reference laboratory of the Brazilian Ministry of Health for the diagnosis of CL. The disease was diagnosed by using: 1) a direct parasite search (DS) in material obtained by scarification of the edge of the lesion after Giemsa staining; 2) an indirect immunofluorescence test (IIF); and 3) the Montenegro skin test $(\mathrm{MST})^{(2)}$. Written informed consent was obtained from patients agreeing to participate in the study. If the patient was a minor, parents or guardians provided consent. This study responded to Resolution No. 196/1996 of the National Council of Health, Ministry of Health (Brazil), and was approved by the Permanent Committee for Ethics in Research Involving Humans of Universidade Estadual de Maringá (Report \# 406/2010).

Polymorphonuclear and mononuclear cells were obtained from $6 \mathrm{~mL}$ of venous blood by using the reagent, Mono-Poly 
Resolving Medium ${ }^{\mathrm{TM}}$ (MP Biomedicals, LLC, France), following the manufacturers protocol. To determine cell viability, $30 \mu \mathrm{L}$ of mononuclear and polymorphonuclear suspensions were subjected to trypan blue exclusion; the cells were then quantified in a Neubauer chamber by using Turk solution and purity was assessed by staining with hematoxylin and eosin. Cells were resuspended in $125 \mu \mathrm{L}$ ACD solution $(25 \mathrm{mM}$ citric acid, $50 \mathrm{mM}$ sodium citrate, $81 \mathrm{mM}$ glucose) and $125 \mu \mathrm{L} \mathrm{NaCl} 0.15 \mathrm{M}$, and were frozen at $-18^{\circ} \mathrm{C}$ until DNA extraction.

Deoxyribonucleic acid (DNA) was extracted using phenol and guanidine ${ }^{(7)}$, resuspended in $50 \mu \mathrm{L}$ TE buffer $[10 \mathrm{mM}$ Tris, $1 \mathrm{mM}$ ethylenediaminetetraacetic acid (EDTA), $\mathrm{pH}$ 8.0] and stored at $4^{\circ} \mathrm{C}$ until use. For each group of 22 samples extracted, we included a positive control [blood of individuals without CL plus $10^{4}$ promastigotes of $L$. (V.) braziliensis] and a negative control (blood from an individual without $\mathrm{CL}$ ).

The primers, MP3H (5'-GAA TTC GGT TGT CGG ATG C-3') and MP1L (5'-ACA TAC GCC TCC CTC TGC TG-3' ${ }^{(8)}$, were used to amplify a 70-bp fragment from the kinetoplast deoxyribonucleic acid (kDNA) minicircles of Leishmania (Viannia). The reaction mixture (final volume: $25 \mu \mathrm{L}$ ) was composed of $1 \mu \mathrm{M}$ of each primer (Invitrogen Life Technologies, São Paulo, Brazil), $1.5 \mathrm{mM} \mathrm{MgCl}_{2}, 1 \mathrm{X}$ enzyme buffer, $0.2 \mathrm{mM}$ dNTP (Invitrogen, Carlsbad, CA, USA), 1UTaq DNA polymerase (Invitrogen, Carlsbad, CA, USA), and $2 \mu \mathrm{L}$ of DNA template. A positive control [1pg of $L$. (V.) braziliensis DNA] and a negative control (water) were included. DNA amplification was carried out in a PCR Thermocycler (Biometra, Germany). The conditions for the PCR were as follows: $95^{\circ} \mathrm{C}$ for $5 \mathrm{~min}$, followed by 35 cycles divided into denaturation $\left(95^{\circ} \mathrm{C}, 1.5 \mathrm{~min}\right)$, annealing $\left(57^{\circ} \mathrm{C}, 1.5 \mathrm{~min}\right)$, and extension $\left(72^{\circ} \mathrm{C}, 2 \mathrm{~min}\right)$. Subsequently, the material was maintained at $72^{\circ} \mathrm{C}$ for $10 \mathrm{~min}$, and the amplified product was stored at $4^{\circ} \mathrm{C}$ until analysis. Ten microliters of amplified products was subjected to electrophoresis in 3\% agarose gel (Invitrogen, Paisley, Scotland, UK), stained with $0.1 \mu \mathrm{g} / \mathrm{mL}$ ethidium bromide, at $10-15 \mathrm{~V} / \mathrm{cm}$. The presence of bands was observed under a transilluminator (MacroVue ${ }^{\mathrm{TM}} \mathrm{UV}-20$, Hoefer, USA).

All samples were tested for the presence of possible inhibitors of PCR by using specific primers for the human $\beta$-globin gene (GH20: 5'-GAA GAG CCA AGG ACA GGT AC-3' and PC04: 5'-CAA CTT CAT CCA CGT TCA CC-3') ${ }^{(9)}$, intended to amplify a fragment of $268 \mathrm{bp}^{(4)}$.

We studied 49 patients ( 41 men and 8 women) with primary lesions positive for $\mathrm{CL}$, the mucosal form, and previous infection. Patients were residents of endemic areas mainly in rural areas.

More than half of the patients, i.e. $53.1 \%$ (26/49) had primary lesions positive for $\mathrm{CL}$ on at least one of the conventional tests used (DS, IIF, or MST). The mucosal form was present in $8.2 \%(4 / 49)$ of patients, and a previous infection was reported in $38.8 \%$ (19/49) of patients. Among the 26 patients with CL, the time for infection of the primary lesion ranged from 20 days to 8 months; 16 patients showed the occurrence of lesion between 1 and 2 months, eight between 3 and 6 months, and two between 6 months and 1 year. Results of a DS were positive in
$80.8 \%(21 / 26)$ of patients with active lesions, while the results of IIF were positive in all 26 patients with a primary lesion, showing titers of up to 320. The MST was conducted in 24 of 26 patients, and 23 (95.8\%) of them showed positive results, with indurations up to $30 \mathrm{~mm}$ in diameter.

Of the 19 patients who reported a previous lesion, 6 exhibited reactivation of a previous lesion, 2 had a new skin lesion, and 11 had returned for treatment monitoring. The time since the appearance of the primary lesion ranged from 2 months to 20 years. Of these 19 patients, DS was only performed in the 8 who currently had skin lesions and only 1 tested positive. The MST was not performed in these 19 patients.

The technique used to obtain mononuclear and polymorphonuclear cells was effective in separating these cells. The viability was $98 \%$ for both polymorphonuclear and mononuclear cells, and the purity was $98 \%$ for polymorphonuclear and $99 \%$ for mononuclear cells. The separation of mononuclear cells indicated mostly lymphocytes $(72 \%)$, followed by monocytes $(28 \%)$; the polymorphonuclear cells were mostly neutrophils (95\%).

The fragment from the kDNA minicircles of Leishmania (Viannia) was detected in mononuclear cells from two patients but was not detected in polymorphonuclear cells (Figure 1). These two patients belonged to the group of $26(7.7 \%)$ patients with active skin lesions for CL, and to the group of $8(25 \%)$ patients who had a lesion with a time for evolution of 3-6 months. All samples were positive for the human $\beta$-globin gene, excluding possible inhibitors of Taq DNA polymerase.

Cutaneous leishmaniasis is a serious worldwide public health issue, endemic in the State of Paraná, with the potential of developing a mucosal form ${ }^{(2)(3)}$. The presence of the parasite in the peripheral blood, as well as in immune cells, may be important for understanding the dynamics of parasite spread in the human body and therefore the pathogenesis of the disease.

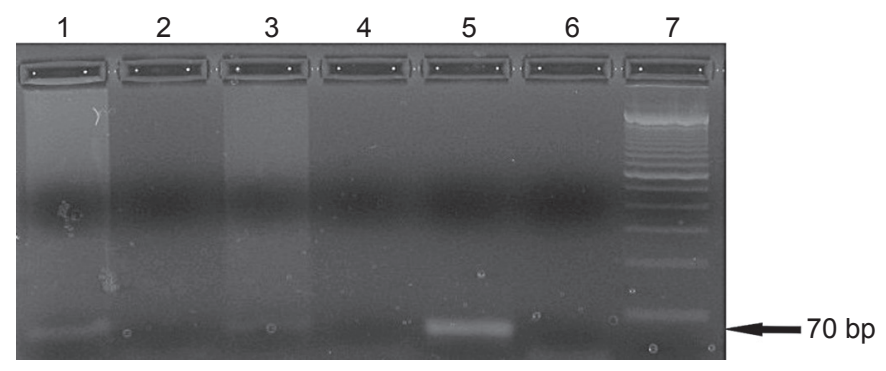

FIGURE 1 - PCR showing the fragment of the 70-bp region of minicircle $\mathrm{kDNA}$ of the subgenus Leishmania (Viannia). Lane 1: mononuclear cell sample from patient A; Lane 2: polymorphonuclear cell sample from patient $A$; Lane 3: mononuclear cell sample from patient $B$; Lane 4: polymorphonuclear cell sample from patient $B$; Lane 5 : positive control [DNA from promastigotes of Leishmania (Viannia) braziliensis]; Lane 6: negative control (water); Lane 7: molecular size of 100bp. PCR: polymerase chain reaction; kDNA: kinetoplast deoxyribonucleic acid; DNA: deoxyribonucleic acid. 
The detection of the parasite in the bloodstream depends on several factors, including the time of sample collection, the patient's immune response, and the spread of the parasite. Despite the possible influence of these factors, our results are meaningful. Parasite DNA was found in two samples of mononuclear cells, and these cells were from two patients with CL. Both these patients had a single, active primary lesion for 3 to 6 months. The presence of Leishmania (Viannia) in mononuclear cells shows that the parasite can be eliminated from macrophages and that it can escape from microbicidal mechanisms and persist in the host ${ }^{(10)}$.

Hematogenous dissemination of the parasite has been considered responsible for the appearance of the mucosal form of $\mathrm{CL}^{(7)}$. Saravia et al. ${ }^{(11)}$ showed that recurrent strains were phenotypically and genotypically identical to initial infection strains in $50 \%$ of the recurrent cases of Leishmania (Viannia) infection in humans, supporting the hypothesis of hematogenous dissemination. Different types of samples have been used to attempt to demonstrate the persistence of the parasite. Romero et al. ${ }^{(12)}$ found parasites in extralesional tissues including scars, normal skin, and monocytes, indicating widespread infection and subclinical involvement of tissues distant from the lesion site. Other studies have shown the persistence of the parasite after clinical treatment, during different stages of treatment ${ }^{(13)}$, and in the blood of a patient 30 years after initial infection and in whom the lesion had healed spontaneously ${ }^{(14)}$.

The hematogenous or lymphatic dissemination of the parasite is the most probable mechanism to explain the occurrence of the mucosal form of the disease and the recurrence of skin lesions ${ }^{(9)}$. The mechanism that triggers the recurrent development of cutaneous or mucosal lesions is not fully understood. The host immune response appears to be crucial in the control and containment of the parasite at the lesion site, and the immunosuppression has been shown as a triggering factor for the reactivation of the disease ${ }^{(15)}$.

Although the presence of Leishmania (Viannia) in mononuclear cells from 2 patients with active CL lesions does not necessarily indicate the existence of viable parasites, it does suggest that monocytes, the host cells involved in parasite defense, can participate in the spread of the parasite. Parasite DNA was relatively rare in peripheral blood cells, but this finding shows probable parasite dissemination that could explain the emergence of subclinical cases, the recurrence of previously treated lesions, and the appearance of mucosal lesions.

\section{CONFLICT OF INTEREST}

The authors declare that there is no conflict of interest.

\section{REFERENCES}

1. World Health Organization (WHO). Control of the leishmaniasis (Internet). WHO; 2013 (Cited 2013 Jun 20) Available at: http://goo. gl/PiM9n

2. Ministério da Saúde. Manual de Vigilância da Leishmaniose Tegumentar Americana [Internet]. Brasília: Editora do Ministério da Saúde; 2013 (Cited 2014 February 11). Available at: http://goo. gl/1BHroN

3. Lima AP, Minelli L, Teodoro U. Tegumentary leishmaniasis distribution by satellite remote sensing imagery, in Paraná State, Brazil. An Bras Dermatol 2002; 77:681-692.

4. Neitzke-Abreu HC, Venazzi MS, Bernal MVZ, Reinhold-Castro KR, Vagetti F, Mota CA, et al. Detection of DNA from Leishmania (Viannia): Accuracy of polymerase chain reaction for the diagnosis of cutaneous leishmaniasis. PloS One 2013; 8:e62473.

5. Ramírez JL, Guevara P. Persistent Infections by Leishmania (Viannia) braziliensis. Mem Inst Oswaldo Cruz 1997; 92: 333-338.

6. Camera PO, Jungera J, Piresa FESS, Mattosb M, Oliveira-Neto MP, Fernandes O, et al. Haematogenous dissemination of Leishmania (Viannia) braziliensis in human American tegumentary leishmaniasis. Trans R Soc Trop Med Hyg 2006; 100:1112-1117.

7. Venazzi EAS, Roberto ACBS, Barbosa-Tessmann IP, Zanzarini PD, Lonardoni MVC, Silveira TGV. Detection of Leishmania (Viannia) DNA in blood from patients with American cutaneous leishmaniasis. Exp Parasitol 2007; 115:399-402.

8. Lopez M, Inga R, Cangalaya M, Echevarria J, Llanos-Cuentas A, Orrego C, et al. Diagnosis of Leishmania using the polymerase chain reaction: a simplified procedure for field work. Am J Trop Med Hyg 1993; 49:348-356.

9. Saiki RK, Bugawan TL, Horn GT, Mullis KB, Erlich HA. Analysis of enzymatically amplified beta-globin and HLA-DQ alpha DNA with allele-specific oligonucleotide probes. Nature 1986; 324: 163-166.

10. Solbach W, Laskay T. The host response to Leishmania infection. Adv Immunol 2000; 74: 275-317.

11. Saravia NG, Weigle K, Segura I, Holmes Giannina S, Pacheco R, Labrada LA, et al. Recurrent lesions in L. Braziliensis infection reactivation or reinfection? Lancet 1990; 336: 398-402.

12. Romero I, Téllez J, Suárez Y, Cardona M, Figueroa R, Zelazny A, et al. Viability and burden of Leishmania in extralesional sites during human dermal leishmaniasis. PLoS Negl Trop Dis 2010; 4: e819.

13. Guevara P, Rojas E, Gonzalez N, Scorza JV, Añez N, Valera M, et al. Presence of Leishmania braziliensis in blood samples from cured patients or at different stages of immunotherapy. Clin Diagn Lab Immunol 1994; 1: 385-389.

14. Guevara P, Ramírez JL, Rojas E, Scorza JV, González N, Añez N. Leishmania braziliensis in blood 30 years after cure. Lancet 1993; 341: 1341 .

15. Ferreira MS, Borges AS. Some aspects of protozoan infection in immunocompromited patients: a review. Mem Inst Oswaldo Cruz 2002; 97: 443-457. 